\title{
LOS EFECTOS DIVERSOS DEL DERECHO COMUNITARIO: EL CASO DE LAS DIRECTIVAS *
}

\author{
Joxerramon Bengoetxea
}

UPV/EHU

RESUMEN. La clásica distinción del Derecho comunitario europeo entre aplicabilidad directa y efecto directo se enfoca desde la no menos clásica distinción entre disposición y norma elaborada por la teoría jurídica analítica. El análisis de los distintos efectos, los efectos diversos, que pueden producir las normas de Derecho comunitario, especialmente las contenidas en directivas, ayuda a entender cuestiones como los efectos directos horizontales, o incluso los efectos indirectos o triangulares que han ido apareciendo en la jurisprudencia del Tribunal de Justicia de las Comunidades Europeas y que tantas dificultades han provocado en la doctrina comunitaria. La riqueza de materiales sobre los que puede volcarse la teoría analítica del Derecho abre nuevas avenidas para la investigación y el mutuo entendimiento entre estas disciplinas.

Palabras clave: directiva, aplicabilidad directa, efectos de las normas, efectos directos, efectos indirectos, efectos triangulares.

ABSTRACT. The classical EC law distinction between direct applicability and direct effect is here analysed from the standpoint of analytical jurisprudence, and especially the distinction it has put forward between provisions and norms, with interpretation as the key factor in the transition. Direct applicability is here seen as a feature of the instruments of the legal order containing provisions whereas direct effect is thought to be a quality of the norms contained in such instruments. These ideas are then carried forward to analyse the diversity of effects which can be produced by norms of Community law and especially by those norms contained in directives depending on the different legal relationships they govern. These approaches shed some light on the new effects produced by directives' norms, according to the case law of the European Court of Justice, like triangular or indirect effects, and which have caused some difficulties to EC legal literature

Keywords: directive, direct applicability, effects of the norms, direct effects, indirect effects, triangular effects.

\footnotetext{
* Fecha de recepción: 7 de enero de 2008. Fecha de aceptación: 31 de enero de 2008.
} 


\section{INTRODUCCIÓN}

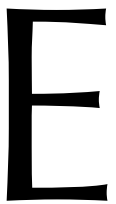

n esta modesta contribución pretendo abordar uno de los aspectos más debatidos de la teoría del Derecho comunitario, el efecto «directo» de las directivas, desde una perspectiva novedosa, como la que aporta la teoría analítica del Derecho, en especial la distinción entre disposiciones y normas, que pondré en relación con la distinción entre aplicabilidad directa y efecto directo. Propondré hablar de los efectos de las normas en general y considerar que la hasta ahora conocida como teoría del defecto directo de las directivas no es más que una de las posibilidades o de las variedades que pueden adoptar los efectos de las normas en el derecho comunitario. Deberíamos hablar entonces de una diversidad de efectos de las normas, de todas las normas, y también lógicamente de las normas de Derecho comunitario. Para ello será necesario, aunque sea brevemente, explicar la teoría del efecto directo en Derecho comunitario.

El principio inspirador del efecto directo es una manifestación de lo que podríamos considerar un principio más general del Derecho comunitario, el principio de efectividad. Este principio jurídico general de efectividad conecta con principios más políticos como el de integración, la unión cada vez más estrecha entre los pueblos de Europa, como reza el preámbulo del Tratado constitutivo de la CE. Se puede observar cómo la pura efectividad no es suficiente si no va acompañada de un consenso sobre la finalidad de las normas cuya efectividad se busca y si no va acompañada de otros valores jurídicos que justifiquen o legitimen dichos fines u objetivos de las normas.

El efecto directo en Derecho comunitario europeo puede caracterizarse como la cualidad de sus normas para crear o generar derechos subjetivos directa y autónomamente en la esfera jurídica de los particulares; derechos que éstos pueden invocar ante las jurisdicciones nacionales y que éstas deben salvaguardar ${ }^{1}$. Esta definición nos sirve como aproximación al fenómeno jurídico conocido como efecto directo del Derecho comunitario aunque deja sin explicar algunos de los desarrollos jurisprudenciales (y posteriormente doctrinales) recientes relacionados con el efecto directo. Es interesante y acertado que se considere al efecto directo como una cualidad de las normas, una cualidad que implica invocabilidad ante los órganos jurisdiccionales. La definición que aporta la Wikipedia va en la misma dirección pero refuerza aún más la idea al extenderla no ya a la posibilidad de ser invocadas sino a la posibilidad de ser ejecutadas, enforceability, lo cual presupone ya la previa alegación de aplicabilidad de dichas normas. Las palabras clave de estas definiciones son: normas comunitarias - derechos subjetivos - creación directa de derechos — esfera jurídica de los particulares-invocabilidad — jueces nacionales u órganos jurisdiccionales internos- obligación judicial de velar por el respeto a dichos derechos.

Algunos de estos conceptos se analizarán más en detalle posteriormente, pero desde este momento se puede apuntar que estos conceptos clave implicados en el efecto directo son los rasgos o componentes esenciales de toda relación jurídica: nos encon-

1 Véase P. AndRÉs SÁENZ de SANTA María, 2006, «Desarrollos recientes de la eficacia directa de las normas comunitaria», en A. SAIZ ARNAIZ y M. ZelaiA (eds), Integración Europea y Poder Judicial, Oñati, pp. 131-156. 
tramos con el titular de una obligación, con su correlativo titular de un derecho, con un objeto de la relación, con su alcance y contenido, con un espacio y un tiempo en los que puede exigirse el cumplimiento de dicho objeto o al menos invocarse ante los órganos judiciales, con las características semióticas del objeto de la relación, es decir la claridad, precisión, certeza, completud, y carácter incondicional de la obligación, la posición institutcional del órgano ante el que se invoca la obligación y que tiene la jurisdicción para hacerla efectiva. Y por supuesto, puede haber más elementos en esta relación jurídica típica, como los terceros afectados, interesados o los terceros con expectativas legítimas, etcétera.

El análisis de la relación del efecto directo debe comenzar siempre con la obligación (elemento deóntico $O$ ) que se impone a una persona $X$ para hacer, no hacer o asegurar algo $F$ a otra persona $Y$ en ciertas condiciones espaciotemporales T. La intensidad del elemento deóntico se convierte en un elemento crucial pero las cuestiones que se deberán resolver no serán siempre las mismas en todas las circunstancias y en algunas situaciones la cuestión a analizar es si una persona $\mathrm{Y}$ tiene el derecho a demandar a $X$ para que ejecute una obligación pero en otras la cuestión será la Comunidad tiene un derecho o un interés en que la obligación $F$ sea ejecutada en las circunstancias $T$. El mismo razonamiento, o lo que parece ser el mismo razonamiento, se aplica así a situaciones potencialmente muy diversas. Las cuestiones que afectan al efecto del Derecho comunitario europeo no son, desde un punto de vista material, muy distintas de las situaciones que surgen conforme al efecto del Derecho interno de un Estado miembro y sería interesante proyectar esta exploración a las normas de derecho interno, algo que escapa del propósito aquí fijado.

El efecto directo no indaga sobre la validez de las normas. Si deseamos analizar las cuestiones de validez no reparamos en aspectos de efectividad, aunque algunas teorías realistas tienden a identificar validez con eficacia o al menos a cuestionar la validez de la norma si se constata su ineficacia ${ }^{2}$. Obsérvese que estamos tratando de conceptos que no siempre se distinguen con nitidez en el lenguaje común, por lo que recurrimos a definiciones postulativas.

Por una parte tenemos la «efectividad» que es la mera capacidad de producir efectos y podríamos asemejar a la operatividad. Por otra parte tenemos la eficacia, que es la capacidad de obtener resultados u objetivos imputables a las normas o al ordenamiento. La eficacia es, al igual que la efectividad, una cuestión de grado en el sentido de que una norma puede ser más o menos eficaz no tanto según el nivel de su observancia sino más bién según se obtengan los resultados u objetivos que persigue. Una norma puede producir efectos mediante su aplicación o incluso mediante su mera validez o existencia y sin embargo no ser eficaz por no alcanzar los resultados que persigue. Por fín está la eficiencia que es una cuestión de economía dentro de la eficacia: es decir, conseguir los resultados con economía de medios, de tiempos o de normas. La eficiencia sería entonces la cualidad valorativamente superior al producir con mayor rapidez y menor costo los resultados perseguidos por la norma. Puede haber eficacia de la norma en el sentido de obtención de resultados y sin embargo no haber eficiencia de la norma por haber desplegado más medios de los necesarios para conseguirlos según

${ }^{2}$ La eficacia de las normas. 
se puede descubrir posteriormente, aunque ésta es en realidad una cuestión empírica y en este punto el lenguaje ordinario no hila tan fino y tiende a considerar ambas cualidades, eficacia y eficiencia, como análogas. Sin embargo desde un enfoque teórico jurídico analítico interesado en las funciones, los efectos y la eficacia de las normas, así como desde una perspectiva de legisprudencia, la distinción puede ser de gran valor.

$\mathrm{El}$ «efecto directo» en el sentido más amplio de la expresión nos proporciona criterios para seleccionar las normas que serán aplicadas o para descartar la aplicación de otras normas, cuya validez no se cuestiona, y para aclarar o precisar el ámbito de la competencia y de la jurisdicción a la hora de aplicarlas haciendo valer derechos e intereses e imponiendo obligaciones. Aunque no afecten a la validez de las normas, estas cuestiones de efectividad y aplicación o inaplicación de las normas siguen siendo de máxima importancia constitucional (federal) ya que implican una interacción entre el legislador supraestatal comunitario que ha adoptado tales normas y el órgano judicial interno que les otorga efectividad y deja sin aplicar normas internas o modifica su ámbito de operatividad, estando ambos órganos situados en planos competenciales distintos y ejerciendo poderes también distintos.

La indagación sobre los efectos jurídicos se puede también poner en relación con la discusión sobre el derecho blando o soft law. El efecto jurídico puede entenderse como un concepto paraguas que abarca no sólo la fuerza jurídica vinculante en sentido estricto sino también otros posibles efectos jurídicos como los que se producen cuando se habla de soft law, o los que incidentalmente se producen por la entrada en escena de otros mecanismos jurídicos como los principios generales del Derecho y de la interpretación jurídica como la certeza jurídica. En esos casos se habla de la producción indirecta de efectos o de efectos jurídicos indirectos ${ }^{3}$. El estudio de la intensidad de los efectos de las normas se convierte así en un tema crucial. Es una tarea que acometeremos más adelante al analizar los efectos de las normas contenidas en las directivas. Una norma puede, en virtud de la relación jurídica que regula y en función de su operador deóntico, vincular a todos los destinatarios de forma plena e incondicional o puede fijar marcar un marco o un espectro de opciones o recomendaciones. Desde un enfoque semántico, conceptual o pandectista, sólo tendremos una aproximación burda de la complejidad de efectos de las relaciones jurídicas. El enfoque pragmático, el análisis institucional y los métodos del análisis sociológico del derecho cobran entonces especial importancia para captar los matices y la amplitud de gama de los efectos jurídicos. Estas ideas deberán cobrar más sentido en el resto de la presente contribución, a la hora de analizar los efectos producidos por las normas contenidas en las directivas.

\section{UN CONCEPTO MUY MANIDO EN EL DERECHO COMUNITARIO}

El efecto directo es objeto de una riquísima literatura en el Derecho comunitario, especialmente en trabajos que comentan la jurisprudencia del Tribunal de Justicia. No debemos olvidar que nos encontramos ante un concepto de filiación jurisprudencial.

3 L. SEnden, 2004, Soft Law in European Community Law, Oxford, Hart Publishing, pp. 236-7. SENDEN trata de analizar tales efectos. Pero el análisis presupone que los efectos jurídicos stricto sensu no se discuten o son pacíficos, lo que supone una premisa demasiado fuerte. 
Sacha PRECHAL, uno de los autores que más extensamente ha escrito sobre el particular, llegó a sugerir hace unos años que era prácticamente imposible aportar algo nuevo sobre el efecto directo ${ }^{4}$. La idea principal en el efecto directo es la posibilidad para un particular de invocar las normas jurídicas comunitarias con el objeto de proteger sus intereses. Interesa resaltar que PERCAL introduce así un Nuevo concepto clave en el análisis del efecto directo, es decir los intereses de un particular mientras que la teoría clásica centraba su atención en los derechos subjetivos.

El análisis de los intereses dentro de la relación jurídica deberá ser aún más sutil que el de los derechos, sobre todo si tenemos en cuenta que los intereses, como los efectos, pueden tener un espectro de grados, intensidades o niveles distintos y que los órganos jurisdiccionales encargados de aplicar el Derecho comunitario tienen que tratar no sólo con normas que reconocen derechos o crean obligaciones sino con todo tipo de normas, incluso aquellas que, sin crear derechos u obligaciones de forma directa, regulan situaciones que dan lugar a que determinados operadores o particulares en determinados momentos invoquen la existencia de dicha regulación para derivar «derechos» e intereses. Equiparar el concepto de efecto directo con la creación de derechos, ignorando elementos como los intereses, restringe innecesariamente el espectro de posibles efectos producidos por las normas jurídicas5.

Además de ser muy abundante la literatura científica, nos encontramos con una impresionante riqueza y casuística jurisprudencial. Lo que ocurre es que la cantidad de sentencias no se ve necesariamente correspondida con su calidad, y menos aún con su claridad. En todo caso, la casuística jurisprudencial va provocando un número cada vez mayor de matizaciones y distingos que van declinando la teoría del efecto directo en virtud de los distintos modos de las relaciones jurídicas afectadas. Esta riqueza convierte a este concepto en uno de los favoritos del análisis doctrinal comunitario, incluido el realizado de forma más estipulativa por los Abogados Generales ${ }^{6}$. Los recovecos adoptados por la teoría o doctrina del Derecho comunitario durante la última década nos presagian que, a fin de cuentas, quizá no se haya dicho aún todo lo que se puede decir sobre el efecto directo: hay espacio para la innovación. La desviación de los derechos hacia los intereses y las distintas intensidades de efectos resultantes son buena prueba de ello. Pero la innovación también es posible desde la perspectiva de la teoría analítica del Derecho y se relaciona con la ya clásica distinción entre disposiciones y normas, las más recientes teorías sobre la derrotabilidad de las normas, o las cuestiones más constitucionales como el principio de lealtad federal previsto en el art. 10 del Tratado CE o el principio de la separación de poderes y de la distribución de competencias entre los

\footnotetext{
${ }^{4}$ «Direct effect reconsidered, redefined and rejected», en J. M. PRINSSEN and A. SCHRAUWEN, 2002 (eds), Direct Effect, Rethinking a Classic of EC Legal Doctrine, University of Amsterdam.

5 La existencia de intereses derivados de situaciones normativas no es exclusiva del derecho como sistema normativo. También en la ética puede suceder que una persona alege un interés concreto que se derive de una situación normativa. Así, dentro de una familia, los hijos tienen interés en la buena comunicación y el cariño entre los progenitores pues ello crea un ambiente propicio para su desarrollo personal y emocional. La obligación jurídica no va más allá del respeto, pero la obligación moral, en al menos una de sus posibles interpretaciones, puede extenderse al cariño o al amor.

${ }^{6}$ Los ejemplos clásicos son las conclusiones de LENZ, VAN GERVEN o JACOBS y sus repetidas admoniciones al Tribunal para que extienda el efecto directo a las relaciones horizontales, algo que el Tribunal rechazó con autoridad en la sentencia Faccini Dori, C-91/92, [1994] ECR I-3325. Sobre este particular, véase A. ARNULL, 2006, The European Union and its Court of Justice, 2nd Edition, Oxford, pp. 225-8
} 
distintos legisladores: entre el poder legislativo y el judicial y entre el plano federal supra-estatal en el que se sitúan los legisladores comunitario (normalmente Consejo y Parlamento europeo que adoptan las directivas) y el estatal (legislador interno que debe transponer la directiva pero puede no hacerlo y el órgano jurisdiccional ordinario de aplicación del Derecho comunitario).

Los grados o intensidades de los efectos de una norma pueden depender de la cuestión si dicha norma se había adoptado con la intención de ser invocada por los particulares ante los tribunales domésticos sin necesidad de una ulterior intervención por parte del legislador doméstico o interno propio del Estado (el central o el regional, según los casos). Aquí nos encontramos con algunos de lo tópicos de la interpretación y el razonamiento jurídicos: todo dependerá de la interpretación sistemática de la norma dentro del ordenamiento, pero el alcance de dicha interpretación puede llevar a prescindir de la necesaria intervención legislativa, lo que nos lleva a una cuestión políticoconstitucional.

Más allá de la cuestión constitucional y analítica, nos encontramos también con las explicaciones del efecto directo desde las teorías de Derecho internacional público que giran en torno a la distinción entre monismo y dualismo. Mediante esta distinción se explican las relaciones entre los ordenamientos jurídicos doméstico e internacional. Bajo la teoría monista, no es necesario un acto concreto de recepción del tratado internacional, bastando con su validez y su asunción por parte del Estado. Mediante las teorías dualistas, de hecho mayoritarias, el Tratado internacional es ratificado e integrado expresamente dentro del ordenamiento jurídico interno. La distinción no debe confundirse con otra igualmente fundamental cual es la de la naturaleza de dichos tratados internacionales como self-executing, en cuyo caso no precisan la intervención ulterior del legislador para ser ejecutables o implementables o non-self-executing, en cuyo caso la precisan antes de poder ser invocados ante los tribunales. Como se ve esta distinción es muy cercana a la del efecto directo de las directivas.

Por todas estas razones, todo análisis del efecto directo del Derecho comunitario deberá adoptar un enfoque no ya pluri-disciplinar sino inter-disciplinar, contrastando sistemáticamente las sugerencias explicativas aportadas por cada enfoque disciplinar.

\section{APLICABILIDAD DIRECTA Y EFECTO DIRECTO; DISPOSICIONES Y NORMAS}

«En todos los Estados miembros existe bastante Derecho (bastante parte del Derecho) que no se puede ejecutar puesto que las reglas que contiene no tienen como su objeto el reconocer derechos ejecutables a los particulares o porque son demasiado vagas o incompletas para ser ejecutadas judicialmente» ${ }^{7}$. Esta intrigante proposición formulada por el profesor Jan WINTER en su artículo seminal sobre el efecto directo abre interesantes avenidas para la teoría del Derecho: problemas de interpretación, sobre todo los relacionados con la intención del legislador, con la vaguedad o la completitud,

7 J. WiNTER, 1972, «Direct Applicability and Direct Effect. Two Distinct and Different Concepts in Community Law», 9 Common Market Law Review 425. 
problemas sobre la naturaleza de las reglas y las normas, problemas relacionados con la ineficacia de las normas, problemas de política judicial relacionados con el activismo o la auto-limitación judicial, en fin, la perplejidad de tratar con un derecho que no es ejecutable pero sigue siendo «derecho» válido y existente. Detrás de este compendio de problemas se encuentra la cuestión que nos ocupa: el estudio de los distintos efectos que pueden producir las normas jurídicas insertadas en órdenes normativos altamente institucionales.

Jan WINTER distinguía entre aplicabilidad directa y efecto directo de un modo que sigue siendo válido en la actualidad, como intentaré explicar sucintamente ${ }^{8}$ poniéndola en relación con otra distinción, entre disposiciones y normas. Las líneas que siguen parten de muchos presupuestos que resultan familiares a los juristas analíticos y por ello no desbrozaré todos ellos. La aplicabilidad directa es una característica de los instrumentos jurídicos, de las fuentes del Derecho y que contienen los textos brutos oficialmente aprobados, es decir el conjunto de disposiciones jurídicas tal y como las formula el legislador. Los instrumentos contenidos en las categorías de fuentes oficiales del derecho comunitario pueden ser vinculantes, como es el caso de los reglamentos o las directivas, o no vinculantes como es el caso de las recomendaciones y los dictámenes. Pueden además ser aplicables directamente o self-executing, como en el caso de nuevo de los reglamentos o no serlo como en el caso de las directivas, que requieren normalmente un desarrollo normativo, una transposición o incorporación en el Derecho interno siguiendo los procedimientos constitucionales internos sobre adopción de instrumentos legislativos, usualmente ${ }^{9}$ mediante la adopción de un instrumento legislativo previsto en la lista de fuentes del Derecho interno: ley (o ley de bases); decreto legislativo, decreto ley, incluso decreto, ley autonómica, etcétera.

Cuando los instrumentos son directamente aplicables o self-executing, como en la tradición monista, se produce una penetración directa del instrumento en cuestión, perteneciente al ordenamiento jurídico supraestatal o internacional dentro del ordenamiento jurídico estatal y todas las normas que pueda contener dicho instrumento a través de sus disposiciones son automáticamente normas del ordenamiento jurídico interno, nacional o estatal o municipal o doméstico, como se le quiera llamar. El caso clásico son los reglamentos, instrumentos comunitarios que, desde su publicación en el Diario Oficial de la Unión Europea, se integran directamente en todos los ordenamientos jurídicos de los Estados miembros. En cambio, como es bien sabido, las directivas no operan de esta manera; son fuentes del ordenamiento jurídico comunitario europeo que vinculan a los destinatarios, los Estados miembros, en cuanto a los resultados u objetivos que persiguen y contienen por tanto obligaciones de resultado, pero no son instrumentos monistas: no tienen la capacidad de penetrar directamente en su ordenamiento jurídico a pesar de retener toda su validez dentro del ordenamiento jurídico comunitario. Para pasar a formar parte del ordenamiento jurídico estatal deben ser

\footnotetext{
${ }^{8}$ He tratado de estas cuestiones en J. BEnGOETXEA, 2003, «Direct Applicability or Effect» (hereafter DAOE) in M. Hoskins and W. Robinson, 2003 (eds), A True European, Essays for Judge David Edward, Oxford, Hart Publishing.

9 Subrayo las palabras «normalmente» y «usualmente» por una razón: no siempre será obligatorio que el Derecho interno se adapte a la directiva tras la adopción de la misma; de hecho puedo ya estar adaptado y conformarse a los objetivos de la directiva, en cuyo caso no será necesaria ninguna intervención legislativa.
} 
transpuestas a dicho Derecho, traducidas a un instrumento característico de dicho ordenamiento, reconocido como fuente de Derecho en una regla de reconocimiento del Derecho interno. La lógica de las directivas es alcanzar los resultados previstos por la misma sin reparar en la formalidad de la fuente que los contenga, cuestión que competerá exclusivamente al ordenamiento jurídico interno. Desde el momento en que la directiva se transpone en el ordenamiento interno, las relaciones jurídicas que contempla se gobiernan a través del instrumento o los instrumentos que han incorporado dichas relaciones jurídicas al derecho interno, pasando la directiva a una especie de stand-by en el ordenamiento comunitario: las directivas siguen manteniendo su vigencia en dicho ordenamiento salvo que ellas mismas prevean su propia caducidad.

Los instrumentos que tienen aplicabilidad directa no precisan de ningún tipo de publicación en el diario oficial del ordenamiento jurídico estatal y pueden por tanto ser considerados como instrumentos que existen en el ordenamiento interno del mismo modo que existen los instrumentos adoptados conforme a dicho Derecho mientras que las directivas no tienen la consideración de instrumentos de Derecho interno y sólo los instrumentos de Derecho que las transponen son los que se publican en el diario oficial estatal. Los particulares no pueden ignorar las disposiciones formuladas en los reglamentos comunitarios ya que éstos reciben la misma consideración que las leyes internas, sin embargo los ciudadanos pueden ignorar las directivas en su totalidad y las disposiciones que formulan ya que se trata de instrumentos dirigidos a los Estados que no tienen, en su cualidad de instrumentos, la virtud de penetrar en el ordenamiento jurídico interno.

En cambio, el efecto directo es una característica no ya de los instrumentos sino de las normas que contienen sus disposiciones. En este sentido, las normas son resultados de interpretaciones de los textos contenidos en las fuentes oficiales, es decir, en las disposiciones que contienen. Las normas son pues el resultado de la interpretación de las disposiciones formuladas por los instrumentos reconocidos como fuentes oficiales de Derecho. Cuando se ordenan y sistematizan las normas se obtiene el concepto de sistema jurídico y las normas cobran su significado institucional, su validez, su vigencia, su ubicación y su alcance dentro del sistema jurídico al entrar en relaciones sistémicas con otras normas. Estas relaciones sistémicas son de jerarquía, de generalidad, de universalidad, de territorialidad, de temporalidad, etc. Las normas jurídicas, derivadas generalmente de una o varias disposiciones contenidas en los instrumentos que conforman el sistema jurídico, pueden también derivarse de otro tipo de fuentes, escritas o no escritas, como por ejemplo, los principios jurídicos o la costumbre o instrumentos no reconocidos como fuente oficial de Derecho pero provisto de normatividad (conocidos como soft law). En este caso no se derivan de disposiciones jurídicas sino de otros elementos. Siempre será necesario examinar si el contenido normativo de un acto se corresponde con el rango formal que pueda haber adoptado, como reconoció con una mezcla de perplejidad y lucidez el Tribunal de Justicia de las CE en la sentencia Grimaldi ${ }^{10}$.

Las normas producen efectos sobre los particulares, sobre todos sus destinatarios (y sobre otros particulares que puedan entrar en relaciones jurídicas con los destinata-

${ }^{10}$ Grimaldi v. Fonds des maladies professionnelles Case 322/88 [1989] ECR 4407. 
rios), dependiendo de múltiples factores como su claridad y precisión, su carácter incondicional o absoluto, la naturaleza o posición institucional de sus destinatarios, sus previsiones temporales (plazos, límites, caducidad, suspensión, vacación), y otros factores como su jurisdicción y territorio o factores procesales como las condiciones de su invocabilidad. Los efectos de las normas dependen sobre todo de sus relaciones con otras normas del sistema, ya que en función de dichas relaciones sistémicas la norma en cuestión podrá ser reformulada, o incluso derrotada, dejada inaplicable en un caso concreto, o ser ella la que derrote total o parcialmente a otras normas del sistema.

El sistema jurídico en la UE es bastante complejo, más aún que el sistema jurídico de los Estados miembros, y del mismo modo que las normas jurídicas entran en relación sistémica con otras normas del mismo sistema, también pueden entrar en relación con otras normas del sistema jurídico interno. En realidad es una cuestión debatible si existen los sistemas jurídicos comunitario y estatal como sistemas separados que entablan relaciones entre sí, o si se trata más bien de constelaciones de sub-sistemas coordinados según el ámbito competencial del que se trate, pero esta cuestión requeriría un análisis separado y detenido que no es el objeto de esta contribución. Nos encontramos en todo caso con un sistema jurídico comunitario que trata de las relaciones federales entre sistema jurídicos distintos y que además debe articular sus propias relaciones con el o los sistemas jurídicos de derecho internacional, por ejemplo, con el sistema del Convenio Europeo de Derechos Humanos, o con los sistemas derivados de ciertos tratados internacionales (Kyoto, OMC, etc.) o con el Derecho internacional público ius cogens. Se produce una compleja división de competencias e incluso en aquellos ámbitos en que los Estados miembros retienen sus competencias siguen teniendo la obligación de respetar y observar el Derecho comunitario, al igual que el Convenio Europeo de Derechos Humanos, o el propio ius cogens internacional. Por ejemplo, aunque los Estados conserven su competencia en materia de imposición directa de las personas físicas, no pueden adoptar normas que supongan una discriminación de los ciudadanos comunitarios: ¿significa esto entonces que el Derecho comunitario prima sobre el estatal por muy competente que sea el Estado miembro en una materia reservada? Sin la primacía del Derecho comunitario, ¿cómo asegurar su unidad? La primacía parece más fácil de asimilar en las materias que los Estados miembros han cedido o transferido a la Unión, bastante más difícil en las competencias mixtas, compartidas pero no asumible en las materias reservadas al Estado.

\section{Breve «divertimento» sobre la primacía del derecho comunitario}

Se produce una unidad última o de última instancia en el sistema jurídico, pero no se trata de una unidad aportada por soberanía o superioridad normativa ex ante del Derecho comunitario uniforme sino más bien por la interpretación y la sistematización jurídicas. No es una unidad político-jurídica determinada por la relación jerárquica entre en Derecho europeo y los Derechos internos. La unidad no se produce ipso facto en el sistema jurídico europeo por el mero hecho de proclamar su primado pero tampoco en el Derecho interno en virtud de la soberanía de la Constitución, pre-existente lógicamente al Derecho comunitario ya que es la Constitución estatal la que habilita la adhesión o integración en el ordenamiento comunitario mediante la cesión de soberanía 
en ciertas materias. Cada una de estas fuentes de unidad está mirando a su propio sistema, y no logra la adhesión incondicional del otro sistema, que por su parte, reivindica su propia soberanía. Estamos entrando aquí en un terreno delicado donde cada sistema se considera supremo y tolera la operatividad del otro, más por un acto de comity o de graciosa concesión que por supeditación o dependencia. El problema puede surgir cuando se trata de elevar la unidad y la primacía al rango de principio consagrado del derecho comunitario, como ocurrió con el Tratado por el que se establecía una Constitución para Europa; entonces emergieron voces críticas.

La primacía del Derecho comunitario declarada reiteradamente por vía jurisprudencial se venía asumiendo por una parte importante de los operadores jurídicos de los Estados miembros, aunque no universalmente y no acríticamente, pero cuando se formuló constitucionalmente, aparecieron las dificultades, especialmente en el Reino Unido, y no sólo por parte de los euro-escépticos. Lo que hasta entonces había sido una práctica jurisprudencial de desplazamiento o dislocación de la norma interna incompatible pasaba a convertirse en una exigencia sistémica de eliminación de la norma interna. Pues bien, se mencione o no el principio de primacía del Derecho comunitario en los textos fundacionales constitucionales como principio básico que gobierna las relaciones entre los sistemas jurídicos implicados ${ }^{11}$, siempre quedará la cuestión compleja de la competencia sobre la competencia, de la aplicación uniforme del Derecho, de la equivalencia de los derechos subjetivos y los remedios procesales, y todas estas cuestiones nos conducen a principios sistémicos que atañen a la interpretación de las normas y sus posibles y diversos efectos o a la diversa intensidad de sus posibles efectos.

Si la primacía se entiende como superioridad jerárquica normativa del derecho comunitario sobre el estatal, es muy posible que cree dificultades: la lex superior parece requerir la derogación de la lex inferior incompatible con ella y la derogación es invasiva; es decir, requiere la eliminación de la norma contraria. Pero puede obtenerse la unidad del sistema mediante otras concepciones de la primacía. Entonces la unidad se produce más bien caso a caso, según las competencias que estén en juego y según la decisión judicial. La norma incompatible de Derecho estatal se deja inaplicada para facilitar la aplicación de la norma comunitaria; es decir, le cede el paso para que pueda aplicarse y gobernar la relación jurídica concreta conforme a sus preceptos, pero no lleva hasta eliminar o derogar la norma interna del ordenamiento jurídico; eso ya no es una exigencia del Derecho comunitario, sino en todo caso, del propio Derecho interno.

\section{LOS EFECTOS DEL DERECHO EUROPEO: DIVERSIDAD DE EFECTOS}

\section{Efectos directos verticales y horizontales}

Los trabajos clásicos sobre el efecto directo distinguen esencialmente dos variedades de efecto directo: el efecto directo vertical — que ocurre cuando las normas de De-

${ }^{11}$ The heated debates over the question whether the Constitutional Treaty or the «reform Treaties» should explicitly mention the primacy of community law have more to do with symbols and tactics than with debats on defeasibility of domestic law and the structural principles of the European legal system. 
recho comunitario se invocan y se aplican en las relaciones jurídicas entre uno o varios particulares y el Estado, en tendido en su sentido más amplio- y el efecto directo horizontal, que se obtiene cuando las normas de Derecho comunitario se invocan y se aplican para gobernar la relación jurídica entre particulares, inter privatos. El concepto de «estado» en Derecho comunitario, para los fines de la aplicación de las normas contenidas en las directivas que se destinan precisamente a los Estados miembros, es muy amplio pues abarca cualquiera de las emanaciones o ramificaciones del Estado desde el conjunto de las administraciones públicas hasta órganos públicos o empresas públicas o empresas con participación pública o cualquier órgano que ejerza, incluso por delegación o subcontratación, autoridad o funciones encomendadas al estado; en general todos los servicios de interés general público ${ }^{12}$. El Estado se trata como una unidad institucional para los fines de la aplicación del Derecho comunitario, que en este caso sigue un principio de personalidad única del Estado, como en el Derecho internacional público, la administración general del Estado personifica al Estado en cualquiera de sus manifestaciones, sin entrar en distinciones sobre cuál pueda ser el órgano concreto que viene afectado directamente por la directiva: es todo el Estado como una personalidad jurídica única aunque se trate de un Estado federal o descentralizado.

Frente a estas distintas expresiones del Estado se pueden invocar las normas contenidas en una directiva: la relación es vertical pues implica a los particulares con los órganos del Estado al que se dirigen las normas. Los efectos horizontales de las normas del Derecho comunitario se producen cuando éste gobierna directamente las relaciones entre los particulares para lo cual es necesario que las normas en cuestión se ubiquen en instrumentos que tengan la capacidad de regular las relaciones inter-subjetivas penetrando en los ordenamientos jurídicos estatales. Como es sabido, estos instrumentos pueden ser los tratados o los reglamentos, o las decisiones individuales dirigidas a los particulares (una decisión en materia de Derecho de la competencia dirigida a las empresas que se encuentran en una entente o cartel o en una propuesta de fusión, etc.).

\section{Efectos verticales ascendentes}

En las relaciones verticales, podemos introducir una matización dependiendo de que la norma se invoque hacia arriba por un particular frente al Estado o hacia abajo por el Estado contra un particular. Así se habla de efectos verticales ascendentes o descendentes. Los efectos verticales ascendentes presuponen la existencia de una obligación clara, precisa e incondicional dirigida al Estado y que no le reconoce a éste ningún ámbito de discreción respecto al alcance, al contenido, a las condiciones de aplicación y a los destinatarios de la obligación. Aquí los efectos se entienden como derechos subjetivos invocables ante los órganos jurisdiccionales internos sobre la base de una obligación que vincula al Estado bien ante los particulares directamente como sería el caso de las normas contenidas en instrumentos o fuentes directamente aplicables - tratados, reglamentos, decisiones- o bien ante otros Estados y ante la propia Comunidad Europea como sería el caso de las normas contenidas en fuentes o instrumentos que no

\footnotetext{
${ }^{12}$ Foster v. British Gas, Case C-188/89 [1990] ECR I-3133.
} 
son directamente aplicables como las directivas. En todo caso el esquema de razonamiento jurídico es hohfeldiano ${ }^{13}$.

En este segundo supuesto, la fuente de la obligación que vincula al Estado miembro y que genera un correlativo derecho subjetivo en el seno de los individuos es el principio de respeto hacia los compromisos contraídos pacta sunt servanda, que impone al Estado honorar u observar sus obligaciones frente a los restantes Estados contratantes y frente a la entidad supra-estatal creada de la cual emana las obligaciones correspondientes (en realidad de un sistema de adopción de decisiones aceptado por todos los Estados miembros donde la Comisión propone y el Consejo y el Parlamento Europeo disponen y en el que todos ellos tienen la oportunidad de participar a través del Consejo). Los particulares pueden invocar la existencia de estas obligaciones contraídas por los Estados en su cualidad de terceros interesados; es decir los particulares derivan derechos e intereses, expectativas, inmunidades, privilegios, a partir de las obligaciones contraídas por los Estados entre sí, adoptadas por la Comunidad Europea y dirigidas a dichos Estados. Un Estado que no respeta las obligaciones que le son impuestas por una directiva está en realidad contraviniendo sus propios actos (venire contra actum propium): es dicho Estado quien ha asumido la obligación correspondiente ante los restantes Estados y ante el ente supra-estatal.

La relación jurídica principal o primaria contemplada por la directiva tiene al Estado como destinatario: impone obligaciones al Estado para que asegure que su ordenamiento jurídico regula las relaciones jurídicas previstas en la directiva del mismo modo que la propia directiva: esas relaciones jurídicas previstas en la directiva son el objeto de la relación jurídica primaria dirigida al Estado. Estas son las coordenadas principales de la relación jurídica primaria de la directiva: su emisor es el legislador comunitario, la CE, su destinatario es el Estado miembro al que se dirija, normalmente cada uno de los Estados miembros y su objeto es la obligación de incorporar las relaciones jurídicas secundarias contempladas en la directiva que supondrán en reconocimiento de derechos o la imposición de deberes. Por tanto, toda pretensión formulada por un particular de derivar un derecho subjetivo a partir de tal relación jurídica será una pretensión basada en la conclusión o derivación lógica a partir de la norma primaria dirigida al Estado miembro; se trataría de una pretensión basada en una norma derivada, como resultado de una operación de interpretación sistémica de la relación normativa primaria.

\section{Efectos verticales descendentes}

Los efectos verticales descendentes operan de forma distinta. Existen instrumentos o fuentes oficiales del Derecho que son capaces, por sí solas, de imponer obligaciones, cargas o prohibiciones a los particulares. Las leyes de los Parlamentos son el ejemplo clásico en los sistemas estatales de fuentes del Derecho. Los Tratados y los reglamentos (también las decisiones) son los instrumentos de Derecho comunitario que pueden penetrar en el ordenamiento jurídico interno y vincular directamente a los par-

\footnotetext{
${ }_{13}$ W. H. HoHFELD, 1913, Fundamental Legal Conceptions, Yale Law Journal.
} 
ticulares: imponerles obligaciones, cargas o incluso sanciones. Por el contrario, las directivas son fuentes que no pueden integrarse en el ordenamiento jurídico interno de los Estados miembros, no tienen fuerza ni rango para ello. Se dirigen a los Estados miembros y son éstos los que deben asegurarse que sus efectos, las normas que contemplan se integrarán en su ordenamiento jurídico interno a través de los instrumentos internos adecuados según el sistema de fuentes vigente en dichos ordenamientos. Las directivas por tanto no afectan a los particulares, no les pueden imponer obligaciones ni prohibiciones ya que sólo se dirigen a los Estados y no a los particulares.

Si a un particular se le pretende imponer una obligación prevista en una directiva, éste podrá oponer una excepción de inaplicabilidad. Es lo que en la técnica jurídica del common law se conoce como estoppel. Es decir, el particular es inmune frente a la directiva, de la cual no es destinatario ni tiene obligación alguna de conocerla. Por tanto la directiva no puede vincular al particular. Las autoridades públicas no pueden por tanto fundarse sobre una directiva para pretender un cumplimiento o una observancia de la misma por parte del particular. Primero deberá transponer o desarrollar o traducir la directiva a su Derecho interno mediante el instrumento jurídico necesario y sólo entonces las relaciones jurídicas tipo previstas en la directiva podrán preverse como relaciones jurídicas tipo en el Derecho interno y sólo entonces tendrán los particulares la obligación de ajustar sus conducta y sus relaciones jurídicas concretas a las previsiones normativas de las relaciones jurídicas tipo. Si el Estado no ha incorporado la directiva, no podrá invocar dichas relaciones jurídicas tipo sin venir contra sus propios actos ${ }^{14}$.

Desde la perspectiva de los particulares, se puede decir que éstos tienen unas expectativas legítimas en el sentido de que las obligaciones que les impone el ordenamiento jurídico vengan contenidas en instrumentos que integren directamente dicho ordenamiento y que les sean destinados a tales particulares. La obligación de los particulares de conocer el Derecho y el principio según el cual la ignorancia del Derecho no exime de su cumplimiento no pueden extenderse a los instrumentos que no van destinados o dirigidos a los particulares. Por el contrario, los particulares pueden ignorar tranquilamente y con la conciencia tranquila aquellos instrumentos que no les van dirigidos sino que se dirigen explícitamente a los Estados. Más concretamente, en el ámbito sancionador el principio general del Derecho que asegura la certeza jurídica, nulla poena sine lege, es de aplicación absoluta: si no existe una lex, no se puede imponer una obligación. Por tanto las directivas que no han sido implementadas no producen, por sí solas, efectos verticales descendentes y no generan obligaciones en el seno de los particulares.

\section{Los efectos directos horizontales}

Una lógica similar a la del estoppel se aplica a la cuestión de los efectos horizontales de las directivas: si las directivas no transpuestas en Derecho interno son incapaces de engendrar obligaciones o cargas en el seno de los particulares, entonces los restantes particulares afectados por las relaciones jurídicas-tipo previstas en las directivas tampoco podrán invocar ante los órganos jurisdiccionales internos la existencia de una obli-

${ }^{14}$ Oficier van Justitie v. Kolpinghuis Nijmegen, case 80/86 [1987] ERC 3969. 
gación de la cual derivarían los correlativos intereses o derechos subjetivos (lo que $\mathrm{HoH}$ FELD posiblemente llamaría no-claim) ${ }^{15}$.

Esto deja al potencial beneficiario de la relación jurídica que no resulta regulada en Derecho interno en una situación de perjuicio o indefensión y al potencial sujeto obligado por la relación jurídica no transpuesta en una cómoda situación de inmunidad. Esta inmunidad y este perjuicio se podrían corregir con la transposición de la directiva, por lo que todo depende de la voluntad o de la decisión del Estado miembro en cuestión de transponer la directiva. Si no lo hace, podrá declararse que está incurriendo en una responsabilidad por los daños que su non transposición pueda ocasionar a los perjudicados por privarles de los derechos subjetivos que hubieran derivado de la correcta transposición o de la correcta regulación de la relación jurídica. La directiva se dirige al Estado miembro y le concede un plazo para la transposición y si no respeta el plazo, podrá declararse que el Estado está incurriendo en un incumplimiento del Derecho comunitario, de la obligación contenida en la relación jurídica primaria de la directiva ${ }^{16}$.

Parece por ello coherente que el Tribunal de Justicia haya desarrollado hace ya tiempo la doctrina de la responsabilidad de los Estados miembros en este tipo de situaciones ${ }^{17}$. La lógica que gobierna este desarrollo jurisprudencial es la de maximizar los efectos de las normas del sistema jurídico comunitario aunque no hayan sido transpuestas al Derecho interno. Las normas contenidas en las directivas no pierden su validez en el sistema jurídico comunitario por el hecho de no haber sido transpuestas al ordenamiento interno. Dicho sea de paso, tampoco la pierden por haberlo sido, sino que mantienen su validez y su existencia en el sistema jurídico europeo y pueden seguir produciendo efectos en dicho derecho y en el derecho de los Estados miembros. La solución contraria supondría que las normas del Derecho comunitario tendrían un bandicap o un defecto que sólo se subsanaría con su correcta transposición donde por arte de magia resucitarían. Sin embargo como argumentamos en este trabajo, el problema no reside en las normas, sino en los instrumentos en que se contienen.

\section{Efecto de reparación}

Nace así un tipo especial de efecto de las directivas: el efecto de reparación, de corrección o de compensación: se invoca ante el Estado miembro incumplidor y su objeto es que compense al particular por los daños que le haya podido generar la falta de transposición de la directiva y la consiguiente privación de los derechos o intereses o beneficios que derivaría de la relación jurídica. Este efecto de corrección o reparación se ha extendido después a otros supuestos análogos de generación de daños a los particulares por el incumplimiento del Derecho comunitario imputable al Estado miembro, elevándolo a principio general del Derecho comunitario, de cuña jurisprudencial.

\footnotetext{
${ }^{15}$ Marshall v. Southampton Area Health Authority, Case 152/84 [1986] ECR 723.

${ }_{16}$ Normalmente, el Estado miembro habrá aceptado el plazo de transposición al negociar la directiva en el Consejo, salvo que haya formado parte de una minoría de voto, lo que resulta muy raro ya que los restantes Estados miembros intentarán adoptar plazos que no resulten demasiado difíciles de cumplir.

${ }_{17}$ Francovich and Bonifaci v. Italy, Joined cases C-6/90 and C-9/90 [1991] ECR I-5357 and Faccini Dori v. Recreb Srl Case C-91/92 [1994] ECR I-3325.
} 


\section{Los efectos de conformidad}

Coherente también con la lógica de otorgar máximo efecto posible a las normas de Derecho comunitario contenidas en las directivas, es la doctrina de la interpretación conforme del Derecho comunitario en general y de las directivas en particular. El Tribunal de Justicia ha derivado esta doctrina de un modo que la aproxima a los efectos directos horizontales aunque la sistemática es bien distinta. En principio, la(s) norma(s) contenida(s) en la directiva prevé(n) o regula(n) una relación jurídica. El resultado que debe alcanzarse por el Estado miembro es la correcta transposición de dicha relación jurídica dentro del plazo fijado por la directiva; ese es el alcance de su obligación. En situaciones normales, el legislador del Estado miembro destinatario adoptará nuevos instrumentos para adaptar su Derecho a las exigencias de la directiva, es decir para asegurarse de que regula las relaciones jurídicas tipo previstas en la directiva de un modo conforme con ésta. Puede resultar que el Derecho interno de un Estado miembro ya regule las relaciones jurídicas del modo previsto por la directiva, en cuyo caso lógicamente no necesitará proceder a la transposición pues la obligación impuesta por la directiva al Estado miembro habrá sido ya satisfecha y el Estado miembro habría estado en conformidad con la directiva desde el momento en que ésta fuera adoptada.

Pero puede ocurrir también que el Estado miembro en cuestión no adopte ningún instrumento de transposición y que su Derecho interno no regula las relaciones jurídicas del modo previsto por la directiva. La pregunta que se puede plantear entonces es si su Derecho interno, las disposiciones de sus distintos instrumentos jurídicos pueden interpretarse de un modo tal que se consiga el resultado impuesto por la directiva al Estado $^{18}$. Estamos ante la problemática de la interpretación conforme. Para los teóricos analíticos de la interpretación jurídica no es ningún misterio que las disposiciones jurídicas contenidas en los instrumentos jurídicamente válidos del Derecho interno sean susceptibles de varias interpretaciones posibles y que potencialmente al menos cada una de estas interpretaciones pueda dar lugar a distintas normas jurídicas. Tampoco es ningún misterio que la elección de una u otra interpretación, y por tanto de una u otra potencial norma se desenvuelva conforme a criterios interpretativos o incluso ideologías de la interpretación que en los supuestos concretos pueden desembocar en resultados bastantes alejados. Pues bien, la doctrina de la interpretación conforme viene a guiar la interpretación introduciendo la máxima según la cual ante varias interpretaciones posibles del Derecho interno se escoja aquella que alcance como resultado la relación jurídica regulada por la directiva. En realidad, como todo analítico de la interpretación habrá observado, estamos ante un campo de minas ya que la propia directiva será a su vez susceptible de interpretación y para saber cuál es o cuáles son las interpretaciones posibles del Derecho interno es necesario haber realizado una interpretación estricta del mismo. La doctrina parece aceptar la corrección de la visión clásica de la interpretación según la cual es posible hablar de una interpretatio contra legem o de una interpretatio praeter legem o secundum legem. En realidad sabemos que se trataría en todo caso de interpretatio contra interpretatio o praeter interpretationis o secumdum interpretationis. Pero lo que la doctrina añade es que si debe forzarse la interpretación

18 Von Colson and Kamann v. Land Nordrheinland-Westfalen, Case 14/83 [1984] ECR 1891 and Marleasing, Case C-106/89 [1990] ECR I-4235. 
del Derecho interno para hacerlo decir algo que no puede decir según los cánones o la práctica de interpretación habitualmente aceptada, entonces no se debe forzar la interpretación ya que muy posiblemente se comprometería la certeza jurídica. Pero si cabe interpretar el Derecho interno de un modo consonante con la interpretación «aceptable» o habitual u ordinaria de la directiva, es decir, si cabe una interpretatio secumdum directivam entonces debe preferirse dicha interpretación sobre las restantes posibles interpretaciones. Como se intuirá, caben múltiples matizaciones sobre las que debemos pasar con rapidez ${ }^{19}$. De lo que se trata esencialmente es de dar efectos máximos a la directiva no transpuesta mediante la interpretación del Derecho interno de un modo conforme a la interpretación de la directiva: una disposición de Derecho interno $D$ no puede ser forzada a librar la norma $N$ que equivale a la norma (interpretada) de la directiva $N$ ' si la norma $\mathrm{N}$ no es una de las interpretaciones aceptables del a disposición $D$. El criterio de aceptabilidad nos remite a consideraciones de orden pragmático sobre la teoría, la doctrina o la ideología de la interpretación comúnmente aceptada en una jurisdicción concreta o en una comunidad concreta de intérpretes jurídicos o en una cultura jurídica concreta ${ }^{20}$.

Otros efectos diversos: triangulares, excluyentes, sustituyentes, escondidos...

Los efectos del tiempo sobre la operación de la norma forman otro de los interesantes efectos diversos que pueden producir las normas de las directivas, hayan sido éstas transpuestas o no o transpuestas correcta o incorrectamente. Como hemos mencionado de pasada, la directiva sigue vinculando a los Estados miembros destinatarios incluso después de su transposición; y es por ello precisamente que se puede contrastar si la transposición ha sido correcta o no, completa o incompleta, algo que la Comisión realizará de oficio y que, en caso de detectar problemas llevará a un cruce de opiniones técnicas con los responsables del Estado miembro. Las normas contenidas en la directiva no dejan de existir o de tener validez dentro del sistema jurídico comunitario por el hecho de haber sido transpuestas al ordenamiento interno. Lo que ocurre es que existirán en instrumentos peculiares que no podrán integrarse en los ordenamientos internos. Uno de los efectos más palpables de las normas de las directivas y de todo el Derecho comunitario será el control de la compatibilidad y por ende la validez de las normas de Derecho interno. Así un Estado miembro, haya o no transpuesto la directiva no podrá adoptar normas que la contradigan pues la directiva sigue vinculando al Estado destinatario, salvo que se haya derogado.

Del mismo modo, la interpretación conforme siempre seguirá inspirando al Derecho interno y el control judicial de la validez del Derecho interno por referencia al Derecho comunitario incluirá las normas contenidas en las directivas, hayan sido transpuestas o no, pues desde la sentencia Foto-Frost dicho control está centralizado en el Tribunal de Justicia que realizará el análisis de la validez (del Derecho comunitario) en función de las normas que integran el sistema jurídico comunitario, donde las directi-

${ }^{19}$ La inspiración en autores como WRÓBLEWSKI, o IGARTUA o GUASTINI no pasará desapercibida.

${ }^{20}$ Me he ocupado de estas cuestiones en distintas publicaciones, entre otras, 2003, «The Scope for Discretion, Coherence and Citizenship» en O. WIKLund (ed.) Judicial Discretion in European Perspective: Stockholm, Norstedts Juridik/Kluwer Law International. 
vas tienen su vigencia, existencia y validez. Incluso al analizar la interpretación del Derecho interno, el juez comunitario interno o supra-estatal podrá decidir que la interpretación correcta de la norma comunitaria derrota o excluye la interpretación habitual de la norma de Derecho interno de forma que esta última deba dejarse inaplicada.

Una cuestión conexa es la de los posibles efectos de las normas contenidas en las directivas aún no transpuestas pero cuyo plazo de transposición tampoco ha vencido. Nos preguntamos entonces por el momento a partir del cual pueda considerarse que las normas contenidas en una directiva cobran su existencia de forma que puedan producir efectos. Esta cuestión se planteó en el asunto Inter-environnement Wallonie ${ }^{21}$. En este caso, una normativa adoptada por la región de Wallonie contradecía claramente las normas de una directiva comunitaria. Pero la normativa valona se había adoptado durante el plazo concedido a los Estados miembros para la transposición de la directiva y no estaba claro si la mera existencia de la directiva publicada, ya en el Diario Oficial impedía la adopción de normas contrarias hasta que se hubiera cumplido el plazo. El Tribunal de Justicia respondió de un modo coherente con la doctrina de los efectos máximos: las normas contenidas en una directiva válidamente adoptada producen efectos desde su adopción y su integración en el ordenamiento jurídico comunitario: obligan a los Estados miembros a no adoptar normas contrarias, aunque les permiten no cumplir con la obligación de transponerlas al Derecho interno hasta que expire el plazo. Las normas de la directiva pueden derrotar a las normas internas incompatibles y son susceptibles de guiar la interpretación conforme de las disposiciones de Derecho interno. No crean obligaciones de adopción de normas de Derecho interno exigibles a los Estados miembros hasta el final del plazo, pero pueden perfectamente usarse como parámetro en el control de la validez de los actos adoptados por los órganos del Estado.

Las obligaciones que imponen las directivas a los Estados miembros pueden generar diversas situaciones que algunos autores califican como efectos de sustitución o efectos de exclusión, o incluso efectos escondidos o efectos triangulares o incidentales y que implican la posibilidad de invocar las normas de una directiva para derivar efectos sobre un particular. Quizá no se trate de la derivación de un derecho subjetivo, pero sí de efectos relacionados con los intereses legítimos que se derivan de las relaciones jurídicas previstas por dichas normas y por el hecho de que se trate de normas que son plenamente vigentes en el Derecho comunitario, aunque no puedan integrarse directamernte en el ordenamiento jurídico interno al no estr contenidas en un instrumento que tenga la capacidad de penetrar dicho ordenamiento ${ }^{22}$.

Estas situaciones analizan las consecuencias normativas que se producen sobre las relaciones jurídicas en el Derecho interno cuando, como resultado de la entrada en escena de una norma contenida en una directiva, las normas de Derecho interno contenidas en legislación interna o en actos administrativos internos se invalidan de forma que los intereses de los particulares afectados por dichos actos o normas quedan afec-

${ }^{21}$ C-129/96 [1997] ECR I-7411.

22 Refiriéndose a casos como Smith \& Nephew and Primecrown, C-201/94 [1996] ECR I-5819; CIA Security v Signalson y Securitel C-194/94 [1996] ECR I-2201; Luxembourg v Berthe Linster e.a. [2000] ECR I-6917; Lemmens C-226/97 [1998] ECR I- 3711; Unilever Italia SpA v Central Food SpA, [2000] ECR I- 7535; Wells C201/02, sentencia de 7 enero 2004 —algunos de estos asuntos implicaban relaciones contractuales otros no, pero todos ellos implicaban la intervención de las autoridades administrativas en el ejercicio de actividades económicas por particulares o la concesión de licencias, autorizaciones de distintos tipos- autores como A. AR- 
tados: en algunos casos se derrota la norma interna y pasa a aplicarse la norma comunitaria y en otros casos no es posible que se aplique dicha norma al no poder penetrar el ordenamiento interno e imponer obligaciones, pero se elimina la norma interna interna que concede algún privilegio de forma contraria a Derecho comunitario. Como resultado de la operación de la norma comunitaria se puede activar una norma interna universal o individual distinta (efectos de sustitución) pero como hemos dicho, en otros casos puede ocurrir que la norma de Derecho comunitario derrote a la norma interna y ninguna otra norma de Derecho interno pase a regular la relación jurídica (efectos de exclusión). En estas situaciones, los efectos sobre los particulares son incidentales, tangenciales, colaterales o escondidos ya que no son los efectos declarados o visibles de las normas. Por eso también se les llama efectos indirectos o inversos. Los efectos de la norma N1 contenida en la directiva es en todos estos casos la derrota de la operación o en una lectura más fuerte la derrota de su existencia-validez de una norma N2 del ordenamiento jurídico interno con el resultado que la relación jurídica gobernada por N2 se altera o se transforma: a veces puede pasar a ser gobernada directamente por N1, otras veces no. Si esta situación puede llevar hasta anular en Derecho interno un contrato jurídico hasta entonces válido es una cuestión que afecta en realidad al Derecho interno y que deberá resolver según su Derecho de obligaciones y contratos, pero desde la perspectiva del Derecho comunitario, lo que sucede es sencillamente la operatividad o efectividad de sus propias normas que pueden derrotar a las internas sin necesariamente llevar a la declaración de su invalidez o inexistencia ${ }^{23}$ sino simplemente a su inaplicación lo cual puede ocasionar una laguna o no, si entran en acción otras normas del Derecho interno, incluido sus principios, o si se interpretan de manera conforme.

Como apuntábamos más arriba, estamos tratando aquí con una derrotabilidad de los efectos de las normas, no tanto de una cuestión de jerarquía entre ordenamientos jurídicos. La derrotabilidad se relaciona así más con los efectos que en la soberanía, o la jerarquía, un término que el tribunal de Justicia ha evitado sistemáticamente en su jurisprudencia. Al dejar inaplicables en los casos concretos las normas incompatibles del Derecho interno se asegura la efectividad de las normas de Derecho comunitario. Para la norma de derecho interno, el resultado no tiene porqué ser ni la invalidez absoluta (inexistencia ex tunc) ni la anulación (invalidez ex nunc en la que algunos efectos pueden mantenerse), pero sí la inaplicación.

NULl, op cit. o S. Weatherill, 2006, Cases and Materials on EU Law, Oxford, usan estos términos. Véase también M. Dougan:, 2007, «When Worlds Collide! Competing Visions of the Relationship between Direct Effect and Supremacy», 44 Common Market Law Review.

${ }^{23}$ G. SARTOR, 1995, «The Defeasibility of Legal Norms», in C. Ciampi, F. Socci, G. TAdDEI Elmi (eds), Atti del V. Convegno InternazionaleI DG Verso un sistema esperto giuridico integrale, Firenze 1993, Padova: Cedam. 